\title{
Trellis Tension Monitoring Improves Yield Estimation in Vineyards
}

\author{
Paul E. Blom ${ }^{1}$ and Julie M. Tarara ${ }^{2,3}$ \\ U.S. Department of Agriculture, Agricultural Research Service, Horticultural \\ Crops Research Unit, 24106 N. Bunn Road, Prosser, WA 99350
}

Additional index words. 'Concord', Vitis labruscana, continuous crop monitoring, crop estimation, yield prediction

\begin{abstract}
Most yield estimation practices for commercial vineyards are based on longstanding but individually variable industry protocols that rely on hand-sampling fruit on one or a small number of dates during the growing season. Limitations associated with the static nature of yield estimation may be overcome by deployment of trellis tension monitors (TTMs), systems that provide dynamic measurement of changes in the tension of the main trellis support wire. In 10 commercial vineyards from which two commercial juice processors annually collect data to derive yield estimates, TTMs were installed. Processor and TTM data were subjected to three permutations of the basic linear computational approach to estimating yield and their accuracies evaluated given known harvested yield at various spatial scales. On average, TTM data produced more accurate estimates of actual yield than did the computational protocols of the juice processors. There was high vineyard-to-vineyard variability in the accuracy of the estimate under all approaches, even from those permutations designed to match the spatial scale of the data collected for yield estimation with the spatial scale of the actual harvested yield. The processor protocols appear to be more sensitive than the TTM approach to the selection of the antecedent years used for comparison with the current year's data. Trellis tension monitoring may be useful to supplant traditional, laborintensive yield estimation practices or to supplement longstanding practices with realtime information that can be applied to dynamic revision of static yield estimates.
\end{abstract}

Given the finite resources of juice processors and wineries, and the perishable nature of the crop, accurate estimation of yield in grapes is crucial for optimal scheduling and processing of the harvest. Difficulties associated with yield estimation in vineyards led to the development of an automated system that also monitors crop growth continuously (Tarara et al., 2004). Longstanding and currently practiced approaches to estimating yield are labor-intensive and tend to rely on only one to two early- to

Received for publication 15 Jan. 2009. Accepted for publication 18 Mar. 2009

John Ferguson provided technical assistance in installation and maintenance of the TTM systems. Todd Elliott and Francis Pierce of the Center for Precision Agricultural Systems at Washington State University developed and provided the data loggers. We greatly appreciate the financial and in-kind support of Milne Fruit Products, National Grape Cooperative, J. M. Smucker Company, the Washington Wine Industry Foundation, and the growers who generously provided access to their vineyards and trellis systems. We thank David Bryla and Justine Vanden Heuvel for critical review.

Mention of a trademark, proprietary product, or vendor does not constitute a guarantee or warranty of the product by the U.S. Dept. of Agriculture and does not imply its approval to the exclusion of other products or vendors that also may be suitable. ${ }^{1}$ Research Biologist.

${ }^{2}$ Research Horticulturist.

${ }^{3}$ To whom reprint requests should be addressed; e-mail jtarara@wsu.edu. midseason snapshots derived from handsampling fruit clusters (May, 1972; Price and Lombard, 1988; Spayd and Wample, 1995), although remotely sensed imaging techniques have been proposed (Dunn and Martin, 2004; Lamb et al., 2004). A general protocol consists of early-season cluster and berry counts and/or mass being recorded from sentinel vines across the contract acreage. These values are compared with those collected during previous years that are considered to be biologically and meteorologically similar to the current growing season. A berry or cluster mass at harvest (i.e., yield) may be projected using a ratio of the current sample value to each comparison year's sample value for the same calendar date or phenological stage. The reported yield prediction may be made by averaging several estimates that were computed using different antecedent years (C. Bardwell, personal communication). Self-reporting suggests that the industrywide accuracy of estimating final yield is $\pm 10 \%$, although this may range up to $20 \%$ or greater in some years (N. Dokoozlian, personal communication) with larger, older operations achieving the best results as a result of adequate staffing for hand-sampling and extensive historical databases.

With its limited sampling frequency, the traditional approach to yield estimation fails to capture the dynamics of berry growth, which can be affected by management practices such as irrigation (Bindon et al., 2008; McCarthy, 1997; Ojeda et al., 2002; Van Zyl,
1984), mineral nutrition (reviewed by Mpelasoka et al., 2003), or crop thinning (Kliewer and Weaver, 1971) and environmental stressors during the season such as berry temperature or exposure to solar radiation (Crippen and Morrison, 1986; Kliewer, 1977; Kliewer and Schultz, 1973; Matsui et al., 1991). The 2005 grape crop in California was a prime example of the failure of the traditional approach (Wine Business Monthly, 2006). Berries enlarged substantially and unexpectedly during the last few weeks of ripening but well after traditional static yield predictions had been made. The extremely large harvest caused turmoil in process scheduling and on the bulk juice and wine market.

Considering temporal limitations along with the cost and practical limitations inherent in the hand-sampling approach, much could be gained from a near-continuous method for monitoring crop development. The trellis tension monitor (TTM) was developed to exploit automated measurements of the tension in the horizontal support wire of the trellis on which grapevines or other trellised crops are trained. The physical principles behind the TTM approach and its initial development in a research setting are described elsewhere (Tarara et al., 2004, 2005). The objective of the present study was to apply the TTM to yield estimation in a number of commercial vineyards from which juice processors annually derive their yield estimates. This report describes the initial performance in yield estimation of the TTM system compared with yields estimated from longstanding protocols of commercial juice processors.

\section{Materials and Methods}

Ten commercial vineyards under contract to two cooperating juice processors were instrumented with TTM systems (Tarara et al., 2004) in south central Washington, the primary juice grape production region in the state $(\approx 10,500$ ha; NASS, 2008). The vineyards had been planted to own-rooted 'Concord' grapevines (Vitis labruscana Bailey) and were between 15 and 35 years old. Vines were trained to a single trunk with a bilateral cordon at 1.3 to $1.7 \mathrm{~m}$ aboveground depending on the vineyard. Vines were winter-pruned annually to six- or seven-node spurs, the standard practice for juice grapes in the region. Trellises included a single horizontal support wire (galvanized, 2.05 to $2.91 \mathrm{~mm}$ diam.) at the height of the cordon, hereafter referred to equivalently as the "trellis wire" or the "cordon wire." Across vineyards, vine spacing varied between 2.0 and $2.4 \mathrm{~m}$ within rows and between 2.7 and $3.0 \mathrm{~m}$ between rows. Depending on the vineyard, wood trellis posts were spaced at every two or three vines (i.e., 4.3 to $7.5 \mathrm{~m}$ ). All vineyards were managed according to accepted local production practices for commercial juice grapes. Eight of the sites were irrigated by overhead sprinkler, whereas the other two sites were irrigated by furrow or by drip. Average annual rainfall in the area is 
200 to $250 \mathrm{~mm}$, falling predominantly between October and April. The 10 vineyards included in the study were managed by seven unique growers and represented the range of historically low- to high-yielding sites among those contracted to our cooperating processors.

At each site, the TTM system was installed in the row adjacent to that containing the sentinel vines sampled annually by the processors. Temperature-compensated load cells (RSC-3K-25100; HBM, Inc., Marlboro, MA) were installed in-line with the cordon wire in 2004 by cutting the wire between two vines and creating small, crimped loops for attachment to the instruments. Turnbuckles were used to connect the assembly and to retension the cordon wire. In a few instances, cordons were trimmed to create space for the TTM and turnbuckle. Trellis wire temperature was measured with a two-terminal integrated circuit temperature transducer (AD590 Two-Terminal IC; Analog Devices, Inc., Norwood, MA) epoxied to the underside of the wire near each load cell.

Data from the TTMs were collected and stored using a spread spectrum radio logger developed by the Center for Precision Agricultural Systems at Washington State University (Model SS100; CPAS Technologies, Prosser, WA). The logger was equipped with a 16-bit A/D converter that had a resolution range of 32,768 steps and was similar to a CPAS model described elsewhere (Pierce and Elliott, 2008) except that a precision 4$\mathrm{V}$ reference was used to excite the load cell. Load cell output signals were proportionate to the excitation voltage. The unit of measurement was the return voltage scaled to the resolution range of the $\mathrm{A} / \mathrm{D}$ converter. Hereafter, trellis wire tension values are reported in the scaled units of the data logger, consistent among TTM installations. Load cell and wire temperature signals were sampled at 5-s intervals and 15-min averages of these data were stored in the radio logger. Data were downloaded to a laptop twice weekly during the growing season (1 Apr. to 1 Nov.) and once weekly in winter. Three full seasons of data were available for yield estimation: 2005, 2006, and 2007.

Data processing. There is a daily fluctuation in trellis wire tension governed by the wire's coefficient of thermal expansion but modulated by the physical connection of the wire to elements of the trellis system, including the vines. The TTM output was corrected for cordon wire temperature using coefficients calculated for each 15-min interval following the procedure in Tarara et al. (2004). During the first season after TTM installation, temperature coefficients were computed dynamically by regressing tension and wire temperature within a 48-h moving window. In analyses after the growing season, data were removed that were known to violate the assumption that all fluctuation in tension during a 48-h period was the result of temperature (e.g., caused by sprinkler irrigation or mechanical damage to the trellis). From the remaining data, we developed a season-average coefficient and then the ten- sion trace was reprocessed. To speed computation during the next year, the previous year's average coefficient was used for dynamic within-season yield estimation. At the close of each year, the moving average filter was applied to the raw data to generate a revised seasonwide average for reprocessing and for dynamic use in the next year. The seasonwide average temperature coefficients were tested for between-year differences within each site using analysis of variance procedures (PROC GLM, SAS Release 9.1; SAS Institute, Cary, NC). Temperaturecorrected tension data were smoothed by computing a daily average value when more than 90 of the 96 possible daily 15 -min values were available.

During March and April, before budbreak, the TTM output stabilized around an annual minimum for 1 to several weeks. We identified this period for each TTM by visual inspection of the tension trace and then calculated an average of these values to best approximate the season's baseline tension value $\left(\mathrm{T}_{0}\right)$ before the start of annual shoot growth. The difference $(\Delta \mathrm{T})$ between the current tension value $\left(\mathrm{T}_{\mathrm{t}}\right)$ and $\mathrm{T}_{0}$ was then plotted in real time. Use of $\Delta \mathrm{T}$ normalizes the data to facilitate intra-annual comparisons among TTM installations and interannual analyses within and among installations. Out-of-range records and anomalies not attributable to environmental transients or vineyard operations were removed from the data. For these records and in the few instances in which data loss occurred as a result of instrument failure, values were estimated by linear interpolation.

Yield estimation. To determine actual yield at the TTM locations, five vines in the same row as and to either side of the TTM were harvested and weighed just before the grower harvested the vineyard by machine. Given the exponential decay in sensitivity with distance from the load cell (Tarara et al., 2004), we expected the first five vines to either side of the load cell to comprise most of the mass contributing to $\Delta \mathrm{T}$. There were two sources of data for deriving yield estimates: 1) the processors' sentinel vines and the growers' machine-harvested fruit, weighed at the processing plant; and 2) the tension data and hand-harvested fruit at the TTM locations. The TTM yields were expressed per unit land area to compare them with the vineyard-level values tabulated by the juice processors.

From TTM data, a daily prediction of final yield was made during 2006 and 2007 with a simple linear function using the known yield and trellis wire tension values from antecedent years:

$$
Y_{t, c}=\left(Y_{a} / T_{t, a}\right) T_{t, c}
$$

where $Y_{t, c}$ is the predicted yield at any time $(t)$ of the current year, $Y_{a}$ is the yield from an antecedent year, $\mathrm{T}_{\mathrm{t}, \mathrm{a}}$ is the trellis wire tension at time $t$ from the antecedent year, and $T_{t, c}$ is the wire tension at time $t$ of the current year. All $\mathrm{T}$ values were normalized (i.e., $\Delta \mathrm{T}$ from the annual baseline, $\mathrm{T}_{0}$ ). There was one antecedent year available in 2006 (i.e., 2005) and two antecedent years in 2007 (i.e., 2005 and 2006). Three predictions were made for 2007: 1) $Y_{t, c}$ using the first antecedent year (2005); 2) $Y_{t, c}$ using the second antecedent year (2006); and 3) a mean $Y_{t, c}$ from the 2005-based and 2006-based predictions.

Dynamic $Y_{t, c}$ values were plotted as functions of calendar time [day of year (DOY)] and thermal time expressed as degree-days $\left(\mathrm{DD},{ }^{\circ} \mathrm{C}\right)$. Comparison of the error in yield estimation when using either DOY or DD as the temporal scale was made using a paired $t$ test procedure (SAS Release 9.1; SAS Institute). Thermal time was computed using a trapezoidal method of integration (Tobin et al., 2001) from 15-min average air temperatures (2-m reference height) obtained from the Washington State University Public Agricultural Weather System (PAWS; now AWNAgricultural Weather Network) station at the Prosser experiment station (http://weather. wsu.edu/). Degree-day accumulation was initiated on Jan. 1 using a $10^{\circ} \mathrm{C}$ lower threshold and no upper threshold. An average of the daily $\mathrm{Y}_{\mathrm{t}, \mathrm{c}}$ values from $\approx 600 \mathrm{DD}$ until harvest provided a smoothed estimate over time $\left(\mathrm{Y}_{\mathrm{est}}\right)$ for comparison with the processorderived static estimates.

The linear function of Eq. [1] was adapted to the static inputs of the processors:

$$
\mathrm{Y}_{\mathrm{est}}=\left(\mathrm{Y}_{\mathrm{a}} / \mathrm{X}_{\mathrm{a}}\right) \mathrm{X}_{\mathrm{c}}
$$

where $X_{a}$ and $X_{c}$ represent the outcomes of the processors' algorithms for antecedent and current years, respectively. Processors define $Y_{a}$ as the mass of fruit weighed on delivery to the processing plant with values representing a range of vineyard sizes (e.g., $\approx 10$ to $100 \mathrm{ha}$ ). To derive $Y_{\text {est }}$, both of the processors cooperating in the study rely on proprietary historical data sets (up to 45 years for Processor A) from sentinel vines distributed across their contracted vineyards. Processor A maintains approximately one sentinel vine for every 5 to 7 ha under contract, whereas Processor B identifies three vines per sentinel vineyard. The contracted acreage is very stable across years. Processor A uses cluster mass as the main input variable for yield prediction, whereas Processor B uses the number of clusters per vine and the number of berries per cluster as main input variables. The general estimation procedure is to select 5 or more years most comparable to the current year in terms of weather, severity of the preceding winter, and the previous year's yield to formulate five or more predictions of the current season's yield that are then averaged. However, with changing vineyard management practices over time, both processors are relying more on data from the most recent 5 to 15 years. For Processor A, current cluster masses (measured $60 \mathrm{~d}$ after full bloom) and those from the antecedent years are used to predict yield for the entire contract acreage processed at its facility. Processor A does not estimate yield at the vineyard scale. Processor B computes 
vineyard scale yield estimates for each sentinel site, which are then averaged across the contracted area to arrive at a regional yield estimate. At our request, Processor A provided cluster mass values obtained between 1998 and 2007 from sentinel vines adjacent to our TTMs and actual yields for each vineyard containing a TTM site. Processor $\mathrm{B}$ provided us with cluster and berry number data, vineyard-specific yield estimates, and actual yields from 2005 to 2007 for each vineyard with a TTM. Both processors shared their proprietary algorithms for formulating $X_{a}$ and $X_{c}$ and requested that the exact computations remain confidential. In practice, the two processors also temper their yield estimates with nonquantified, subjective inputs that vary by situation and the experience of the estimator. We did not include any of these nonreproducible adjustments in our analyses.

The relative accuracy of $Y_{\text {est }}$ derived from TTM and processor data were assessed by calculating an estimation error, $\mathrm{Y}_{\mathrm{err}}$, as:

$$
\mathrm{Y}_{\mathrm{err}}=\mathrm{Y}_{\mathrm{est}, \mathrm{i}}-\mathrm{Y}_{\mathrm{a}, \mathrm{i}}
$$

where $Y_{\text {est, } i}$ is estimated and $Y_{a, i}$ is actual harvested yield as defined for each of the comparative approaches that are described subsequently. The estimation error was expressed as a percent of $Y_{a}$, in which negative values indicate underestimation and positive values overestimation. All yields are expressed in $\mathrm{t} \cdot \mathrm{ha}^{-1}$.

Because of differences in spatial scale at which sampling occurred and for which yield estimates were derived, we devised three computational approaches to elicit reasonable comparisons between $\mathrm{Y}_{\text {est }}$ obtained from TTM data and $\mathrm{Y}_{\text {est }}$ from the processors' inputs. First, we compared outcomes from Eqs. [1] and [2] essentially as each is normally applied in practice (i.e., without regard for spatial scale). Under this approach, $\mathrm{Y}_{\mathrm{a}}$ for the TTM was that hand-harvested from the 10 vines nearest the load cell (five vines to either side of the load cell, all in the same row). For the processors, $\mathrm{Y}_{\mathrm{a}}$ was that delivered to the processing plant by the grower and weighed at the delivery scales. Because Processor A does not predict vineyard-specific yield, we did so for each experimental site by inputting the processor's raw data and applying its standard algorithm to 8 antecedent years. A mean of the eight $Y_{\text {est }}$ was retained.

Under a second comparative approach, the mass of fruit hand-harvested from the 10 vines nearest the TTM (same row as load cell) was defined as $Y_{a}$ for both the TTM and the processors' sentinel vines, thereby constraining yield predictions to the same spatial scale as the input data. Because fruit on the processors' sentinel vines is sampled destructively, these vines cannot be used to define $\mathrm{Y}_{\mathrm{a}}$. Temporally, input data from Processor A were limited to 2005, 2006, and 2007, the same years available for Processor B and the TTMs. We simplified the comparisons in 2007 by constraining $\mathrm{Y}_{\text {est }}$ for the TTM to a single value derived from the mean of the two predictions using single antecedent years (i.e., 2005 and 2006 independently).

A third approach partly addressed the practical issue of "scaling up" by comparing $\mathrm{Y}_{\text {est }}$ for the TTM with $\mathrm{Y}_{\mathrm{a}}$ at the vineyard scale (i.e., 10 to $100 \mathrm{ha}$ ) as recorded by the processors in the fruit weighed at delivery to the processing plant. TTM-derived $\mathrm{Y}_{\mathrm{est}}$ were computed as under the second approach. Processor input data again were limited temporally to the same antecedent years that were available for the TTMs (i.e., 2005 for predicting yield in 2006; the mean of 2005 and 2006 for predicting yield in 2007). Therefore, $Y_{\text {est }}$ and $Y_{\text {err }}$ for the processors differ from those under the first approach; $Y_{a}$ is identical.

Damage to the trellis in one vineyard (Site 3) during harvest in 2005 forced relocation of the TTM to an adjacent row, rendering 2005 TTM data meaningless for prediction of 2006 or 2007 yields. Also in 2005, the same vineyard was mechanically crop-thinned in all rows except that containing the TTM. Actual yield values for the TTM (10-vine handharvested) could not be compared with vineyard scale $\mathrm{Y}_{\mathrm{a}}$ in that year. We excluded Site 3 from all yield analyses.

\section{Results and Discussion}

Data processing. Season-average temperature correction coefficients were calculated for each TTM in each year because the trellis wire expands and contracts relative to the conditions under which the TTM functions as part of an integrated physical and biological system. Individual sites' coefficients differed significantly $(P>F=0.009, \mathrm{df}=2)$ among seasons, so year-specific coefficients were used to correct $T_{t, c}$ for wire temperature (Table 1). However, temporal differences generally were small with a median value across all sites of $8.0 \%$ between years. For what might be considered the most stable installation, the temperature correction coefficient changed by $5.1 \%$ from 2005 to 2007 , whereas for what might be considered the least stable installation, the temperature correction coefficient changed by $17.4 \%$. The largest differences were among TTMs in any year (e.g., 2007 range, -16.4 to $-54.9^{\circ} \mathrm{C} /$ unit tension), indicating the importance of adopting site-specific temperature correction coefficients. Actual wire temperature should be used as opposed to air temperature or other analog, because the spatially variable radiation load on the wire can cause diurnal hysteresis (Tarara et al., 2004).

Per TTM, $\mathrm{T}_{0}$ usually was lower in the current year than in the previous year (Table 2 ). In one case (Site 3 ), the change was the result of relocation of the equipment after damage to the trellis during the mechanical harvest in 2005. Excluding Site 3, the most stable $\mathrm{T}_{0}$ declined by $8.3 \%$ over the three seasons; the median difference across sites was $-29 \%$. The tendency for $\mathrm{T}_{0}$ to decline between seasons may have been driven by a gradual process by which wire tension along the row regains an equilibrium after the disturbance of TTM installation. Also over time, trellis posts may shift and staples loosen. In the longer term, as cordons enlarge over the years, their localized attachment to or enveloping of the trellis wire changes. Trellis wires do stretch over time, the practical effect of which is known by growers, who periodically inspect trellises during the dormant season and occasionally retension cordon wires. However, the pertinent time scale of most of these changes is over multiple seasons rather than during short periods within a growing season, which substantiates the functionality of the TTM for within-season yield estimation. The sensitivity of the TTM is a function of $\mathrm{T}_{0}$ (Tarara et al., 2004), so if $\mathrm{T}_{0}$ drifts excessively, a cautionary approach may be warranted for interannual comparisons that are separated by many years.

There was no significant difference between using calendar and thermal time $(\mathrm{t}=1.53, \mathrm{df}=29, P>|\mathrm{t}|=0.1368)$ as the temporal scalar of $\Delta \mathrm{T}$. The $\mathrm{DD}$ scale was adopted to reduce more of the variability generated by slight phenological asynchrony among years that was observed under DOY scaling. For the data to be most useful for yield prediction and crop monitoring, an accurate scalar quantity of $\Delta \mathrm{T}$ resulting from canopy and fruit growth should be determined. The tension trace also should be corrected for changes in wire tension that are not induced by the vine. Throughout the study, most perturbations to $\Delta \mathrm{T}$ that were detected by the TTMs but that were not related to crop growth were corrected by a systematic offset. These perturbations tended to be of two kinds. The first, a transient effect caused by rain or overhead irrigation, increased tension briefly, after which $\Delta \mathrm{T}$ returned to its previous trajectory and the temporary offset was removed (Fig. 1A). Our use of daily averages to smooth the data damps the apparent amplitude of the perturbation and increases its apparent duration. This intermittent disturbance does interfere somewhat with the goal of a smooth tension trace for yield estimation, but it also indicates a peripheral usefulness of allowing the grower to confirm remotely that irrigation, for example, was applied when scheduled.

Table 1. Seasonal average temperature correction coefficients for each trellis tension monitor (TTM) installation.

\begin{tabular}{cccccc}
\hline & \multicolumn{5}{c}{ Coefficients $\left({ }^{\circ} \mathrm{C} / \text { unit tension }\right)^{\mathrm{z}}$} \\
\cline { 2 - 6 } TTM & 2005 & 2006 & 2007 & Mean & SE \\
\hline 1 & -29.67 & -25.87 & -27.11 & -27.55 & 1.117 \\
2 & -14.79 & -13.91 & -16.43 & -15.04 & 0.738 \\
3 & -36.84 & -34.68 & -30.93 & -34.15 & 1.729 \\
4 & -21.31 & -23.36 & -20.10 & -21.59 & 0.951 \\
5 & -27.41 & -23.00 & -25.81 & -25.41 & 1.288 \\
6 & -35.20 & -29.58 & -29.09 & -31.29 & 1.961 \\
7 & -34.29 & -34.95 & -29.06 & -32.77 & 1.862 \\
8 & -59.01 & -58.66 & -54.93 & -57.53 & 1.307 \\
9 & -52.93 & -53.07 & -50.25 & -52.08 & 0.919 \\
10 & -37.35 & -39.39 & -34.75 & -37.16 & 1.343 \\
\hline
\end{tabular}

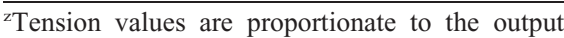
signal voltage scaled from 1 to 32,768 . 
Table 2. Baseline tension $\left(\mathrm{T}_{0}\right)$ for each trellis tension monitor (TTM) installation computed from an average $T_{t, c}$ during the 6 weeks before budbreak.

\begin{tabular}{rrrr}
\hline & \multicolumn{3}{c}{$\mathrm{T}_{0}{ }^{\mathrm{z}}$} \\
\cline { 2 - 4 } TTM & 2005 & 2006 & 2007 \\
\hline 1 & 2400 & 2350 & 2200 \\
2 & 1635 & 1150 & 1465 \\
3 & 1300 & 500 & 575 \\
4 & 2800 & 2300 & 2000 \\
5 & 2300 & 1775 & 1445 \\
6 & 1900 & 1300 & 1250 \\
7 & 3075 & 2175 & 1750 \\
8 & 4910 & 4560 & 4225 \\
9 & 2500 & 2430 & 1945 \\
10 & 2900 & 2230 & 1715 \\
\hline
\end{tabular}

zTension values are proportionate to the output signal voltage scaled from 1 to 32,768 . where (unpublished data) indicated that potential short-term changes in plant hydration after drip irrigation might be detectable in the tension trace. The second type of perturbation imposed a persistent effect for the remainder of the season (Fig. 1B), the causes of which were not readily identifiable because the extent of recordkeeping varied tremendously among growers. Across the entire database, we were unable to identify causes for a small number of persistent shifts in wire tension that may have been associated with vineyard management activities (e.g., breaking and repair of cordon wire, post replacement, accidental damage to the trellis by farm equipment). Details of daily or weekly vineyard operations will aid in inter-

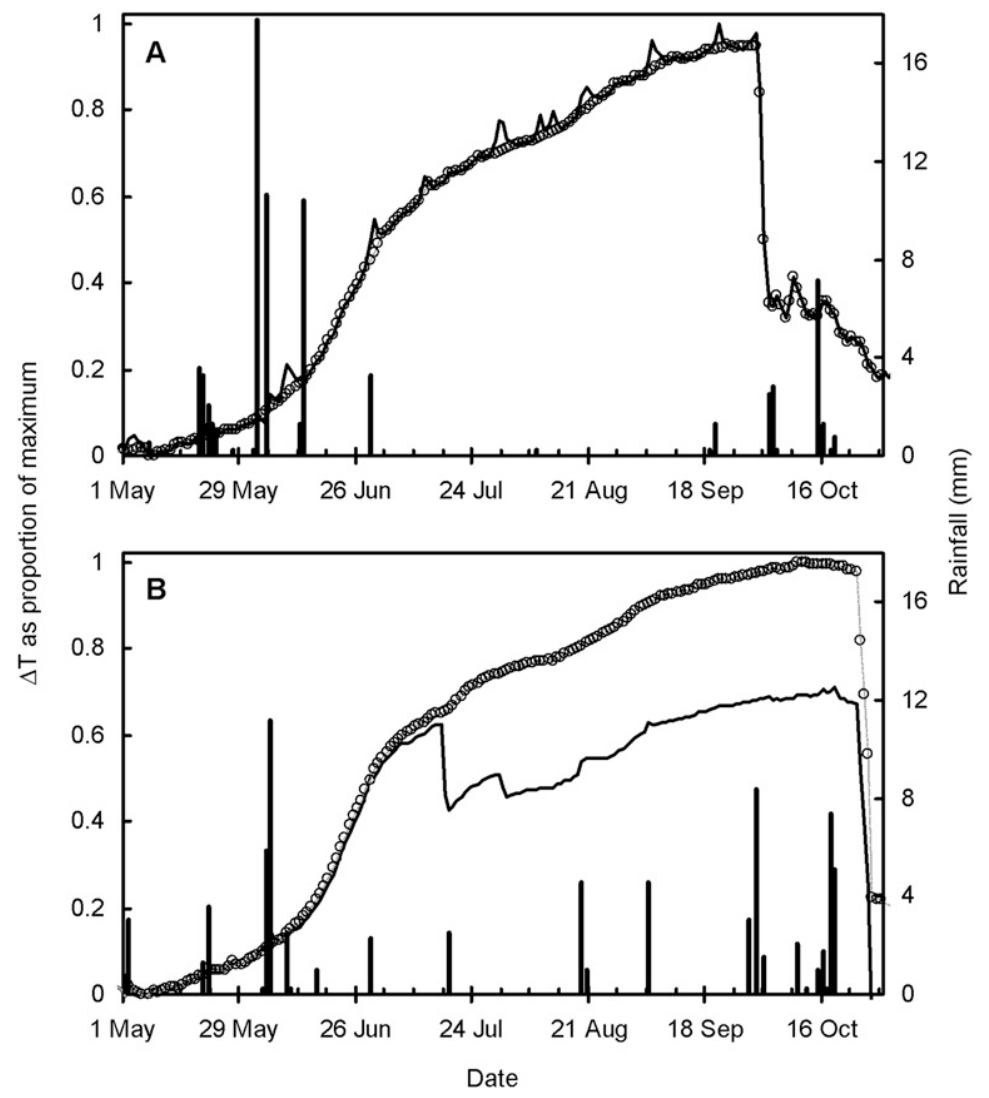

Fig. 1. Single-season tension traces for two Trellis Tension Monitors (TTM), one in a vineyard (A) irrigated by overhead sprinkler (Site 7, 2006) and the other in a vineyard (B) irrigated by furrow (Site 4, 2007). The TTM output ( $\Delta \mathrm{T}$; solid line) was corrected for the temperature of the trellis wire and normalized to a mean prebudbreak value. Open circles represent the adjusted tension trace corrected for intermittent disturbances to the trellis that were detected by the TTM but were not related to crop growth. A shows transient spikes in $\Delta \mathrm{T}$ resulting from repeat applications of overhead sprinkler irrigation. B shows two drops in $\Delta \mathrm{T}$ that persisted, the sources of which could not be determined. Vertical bars are rainfall events.

We interpret the irrigation perturbation under sprinkler to be predominantly the result of water mass on the canopy, readily detected by the TTM, and possibly plant hydration, which on its own may not be of a detectable magnitude in well-watered vineyards. In furrow- (Fig. 1B) or drip-irrigated vineyards (data not shown), the effect of irrigation on plant hydration was not necessarily evident. However, preliminary examination of TTM data from a deficit-irrigated vineyard else- preting unexpected changes in the TTM output signal. Adjusting the tension trace is reasonable and it will be important to develop offset techniques in vineyards where intentional changes occur to the mass being supported by the trellis wire (e.g., shoot thinning).

Yield estimation. The dynamic $\mathrm{Y}_{\mathrm{t}, \mathrm{c}}$ from the TTM [Eq. (1)] oscillated dramatically in the early part of the season (Fig. 2). Before bloom, such yield estimates essentially are irrelevant, reflecting $\Delta \mathrm{T}$ attributable specifically to canopy growth. It is only after bloom that a fraction of the seasonal $\Delta \mathrm{T}$ may be attributed to fruit mass. About DOY 180 or $\approx 600$ DD, day-to-day variability in $\mathrm{Y}_{\mathrm{t}, \mathrm{c}}$ diminished greatly (Table 3; Fig. 2). The time at which yield estimates stabilized coincided with the approximate time at which one would expect the canopy to approach an estimated lower bound on its maximum mass (Tarara et al., 2009) for vineyards in our area. Among sites, the variability in this response was fairly small in both years (data not shown) despite differences in vineyard age, grower management approach, and actual yields.

The earliest static yield estimates may be based on the number and size of cluster primordia as determined by dissecting dormant buds (L. Sanchez, personal communication) or more simply by the number of nodes per vine after pruning (Folwell et al., 1994). Beginning with a prebudbreak prediction, Folwell and colleagues (1994) found that static yield estimates for the regional 'Concord' crop were progressively more accurate as new data on actual crop mass (i.e., cluster mass per vine and/or berry mass per cluster) became available for incorporation into the variously parameterized models. The number of clusters per vine and the number of berries per cluster were significant terms in all models for which they were possible inputs, providing statistical support to the main input variables relied on by processors. By contrast, the uniqueness of the TTM is its continuous output related directly to a dynamic, integrated change in plant mass and thus the potential for continuous revision of yield estimates from a single set of model parameters.

Under the first comparative approach (native protocols), $\left|\mathrm{Y}_{\mathrm{est}} \mathrm{Y}_{\mathrm{a}}\right|$ varied greatly among sites for both TTM and processor procedures (Table 4). On average in 2006, the accuracy of the TTM $\left(17.5 \%\right.$ mean $\left.\left|Y_{\text {err }}\right|\right)$ in estimating $\mathrm{Y}_{\mathrm{a}}$ for the vines nearest the load cell using a single antecedent year was slightly worse than that of the processorbased protocol $\left(14.6 \%\right.$ mean $\left.\left|Y_{\text {err }}\right|\right)$ in estimating vineyard scale $\mathrm{Y}_{\mathrm{a}}$ using a mean prediction from 8 antecedent years. In 2007,

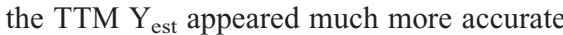
$\left(9.9 \%\right.$ mean $\left.\left|Y_{\text {err }}\right|\right)$ than processor estimates (20.6\% mean $\left|\mathrm{Y}_{\text {err }}\right|$ ) with the use of 2 antecedent years for the TTM providing the best average result $\left(\left|\mathrm{Y}_{\text {est- }} \mathrm{Y}_{\mathrm{a}}\right|=2.7 \mathrm{t} \cdot \mathrm{ha}^{-1} ; \mathrm{n}=\right.$ 9). When using a single antecedent year for TTM estimates in 2006 and 2007, $\mid \mathrm{Y}_{\text {est }}-\mathrm{Y}_{\mathrm{a}}$ averaged $3.4 \mathrm{t} \cdot \mathrm{ha}^{-1}(\mathrm{n}=27,14.2 \%)$. By comparison, the processors' $\left|Y_{\text {est }}-Y_{a}\right|$ averaged $4.4 \mathrm{t} \cdot \mathrm{ha}^{-1}(\mathrm{n}=18)$ or $17.6 \%$ over both years. At Site 7 in 2007, the processors' computational protocol produced the highest single $\mathrm{Y}_{\mathrm{err}}(52 \%)$ with a prediction of 42.5 $\mathrm{t} \cdot \mathrm{ha}^{-1}$ for an actual yield of $28.0 \mathrm{t} \cdot \mathrm{ha}^{-1}$. The processor protocol overestimated yield from two vineyards and underestimated yield from seven in that year. The TTM, using 2 antecedent years, was about as likely to under- as to overestimate actual yield. 


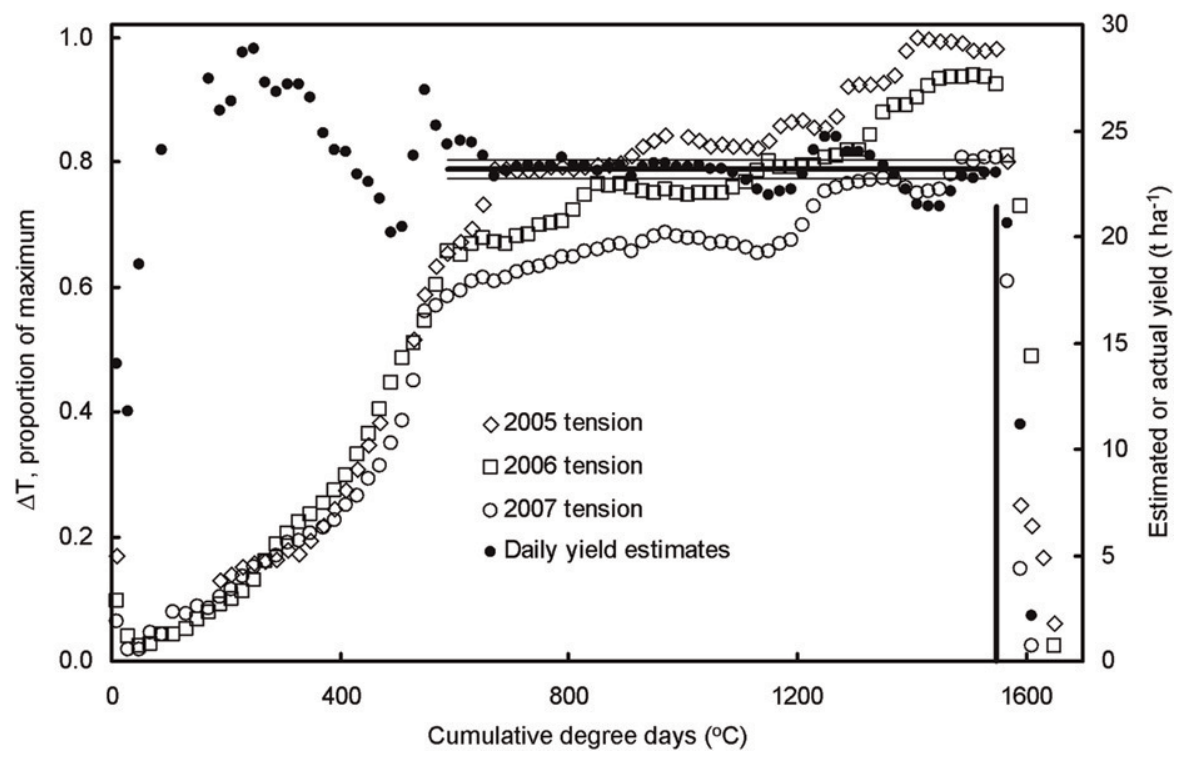

Fig. 2. Dynamic yield estimation for 2007 at Site 10 applying Eq. [1]. Thin horizontal lines indicate average of daily estimates over the range 590 to 1530 degree-days $\left(\mathrm{Y}_{\text {est }}\right)$. The top line represents $\mathrm{Y}_{\text {est }}(23.6$ $\left.\mathrm{t} \cdot \mathrm{ha}^{-1}\right)$ using 2005 tension and known yield data alone. The bottom line represents $\mathrm{Y}_{\text {est }}\left(22.7 \mathrm{t} \cdot \mathrm{ha}^{-1}\right)$ using 2006 tension and known yield data alone. The heavy horizontal line represents $Y_{\text {est }}$ resulting from averaging the 2 input years $\left(23.2 \mathrm{t} \cdot \mathrm{ha}^{-1} ; 8.4 \%\right.$ overestimate of actual yield). Vertical bar represents actual yield in 2007 .

Table 3. Day of year (DOY), cumulative thermal time [(degree days (DD), $\left.{ }^{\circ} \mathrm{C}\right]$, and number of days after full bloom (DAB) when the day-today variability of individual yield estimates from trellis tension monitor (TTM) data appeared to stabilize during the 2007 growing season. ${ }^{\mathrm{z}}$

\begin{tabular}{cccc}
\hline TTM & DOY & DD & DAB \\
\hline 1 & 174 & 550 & 24 \\
2 & 177 & 630 & 27 \\
3 & 181 & 590 & 31 \\
4 & 179 & 570 & 29 \\
5 & 184 & 590 & 34 \\
6 & 180 & 550 & 30 \\
7 & 180 & 650 & 30 \\
8 & 180 & 530 & 30 \\
9 & 186 & 610 & 36 \\
10 & 182 & 590 & 32 \\
Mean & 180 & 586 & 30 \\
SE & 1.1 & 11.8 & 1.1 \\
\hline
\end{tabular}

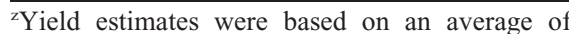
predictions generated against the 2005 and 2006 tension and known yield data.

A processor's target for a composite regional yield estimate is $\pm 5 \%$ of $\mathrm{Y}_{\mathrm{a}}$, but the data (Table 4) show that $Y_{\text {err }}$ can be much higher than that for individual vineyards. In practice, industry estimation protocols often include a variety of nonquantified or ambiguous inputs to refine individual estimates, rendering many yield predictions tenuous combinations of science and art. Thus, the cooperating processor would have adjusted downward the unrealistically high $\mathrm{Y}_{\text {est }}$ of Site 7 (2007) subjectively based on the processor's knowledge of that vineyard's history as an average-yielding sentinel site. Objective yield estimation procedures may neglect factors that are not readily quantifiable but that do influence yield as suggested in the out- comes of a regional forecast model (Folwell et al., 1994). Nonetheless, for the most reasonable and rigorous potential comparisons in this study, we did not include any of the processors' subjective adjustments either to input data or to the resulting $\mathrm{Y}_{\text {est }}$.

Under the constraints of the second comparative approach (TTM and processor methods limited to the spatial scale at which input data were recorded; $Y_{a}$ from TTM used for both methods), the values for the TTM are identical to the first set of comparisons with 2007 values representing the mean of two predictions derived from the 2005 and 2006 data independently. We limited the processor-based inputs to the same antecedent years as the TTM. Because TTM fruit were harvested within a few meters of the processors' data vines, we expected similarity between processor predictions and those from the TTM data. However, the opposite occurred with an overall mean $\left|Y_{\text {est }}-Y_{a}\right|$ from the processors' methods of $14.3 \mathrm{t} \cdot \mathrm{ha}^{-1}$ or $60.4 \%$ $(\mathrm{n}=18$; Table 5). The TTM appeared to be a better estimator of vines in its vicinity than were the processors' sentinel vines, especially when historical data were restricted. From the processors' methods, $\mathrm{Y}_{\text {est }}$ was an overestimate in seven vineyards in 2006. There was an equal tendency toward overand underestimation in 2007. High vine-tovine variability appears to have driven the large difference between the TTM and processor-based estimates of identical $\mathrm{Y}_{\mathrm{a}}$ values. Despite constraints on time and labor, processors might consider increasing the number of sentinel vines per site for vineyard scale prediction or to decrease the number of hectares represented by each sentinel vine. However, a discussion of adequate sample sizes is beyond the scope of this report.
Considering the processors' ultimate goal of producing a regional yield estimate, we devised the final comparative approach: "scaling up" both methodologies to the level of vineyard estimation $\left(\mathrm{Y}_{\mathrm{a}}\right.$ weighed at the processing plant for both estimation methods) while restricting antecedent data to those years available for the TTM. The accuracy of TTM-based $\mathrm{Y}_{\text {est }}$ generally was higher than that of the processor-derived $\mathrm{Y}_{\text {est }}$ (Table 6). As expected with application to a larger spatial scale, $\left|Y_{\text {err }}\right|$ from the TTM were larger than under the first computational approach, averaging $4.8 \mathrm{t} \cdot \mathrm{ha}^{-1}(\mathrm{n}=27)$, or $20.0 \%$. Again, the average $\left|Y_{\text {err }}\right|$ was lower in $2007\left(2.7 \mathrm{t} \cdot \mathrm{ha}^{-1}\right.$ or $\left.9.9 \% ; \mathrm{n}=9\right)$ when estimates from both antecedent years (2005, 2006) were averaged. Absolute errors in the processors' estimates were very high, averaging $13.1 \mathrm{t} \cdot \mathrm{ha}^{-1}$ or $59.8 \%(\mathrm{n}=18)$. Because the magnitude of $\mathrm{Y}_{\mathrm{err}}$ in the processor-based estimates was similar regardless of the spatial scale of $Y_{a}$, the processor method appears to be more dependent on the selection of appropriate and perhaps an adequate number of antecedent reference years. Choice of reference year is made a priori, the effect of which was made apparent in 2005 when highlighted by the California grape crop (Wine Business Monthly, 2006).

With decades of data on cluster numbers and cluster masses, processors can fine-tune, albeit quite subjectively, their selection of comparative antecedent years. The 2005 and 2006 seasons may not have been the most suitable for processor-derived $\mathrm{Y}_{\text {est }}$ in 2006 and 2007. By comparison, the TTM performed reasonably well without subjective assessment and $\left|Y_{\text {err }}\right|$ decreased considerably by using 2 rather than 1 antecedent year to derive $\mathrm{Y}_{\text {est }}$. It would be reasonable to expect even lower $Y_{\text {err }}$ from TTMs as longer historical data sets become available. In this study, the TTM system had an advantage of spatial scale over traditionally computed $\mathrm{Y}_{\text {est }}$ in that both $\mathrm{Y}_{\text {est }}$ and $\mathrm{Y}_{\mathrm{a}}$ for the TTM were based on fruit within $\approx 12 \mathrm{~m}$ of the load cell ( $\mathrm{n}=10$ vines). For larger-scale estimation, questions of sample size and TTM location must be addressed as also is the case for traditional hand sampling. When $\mathrm{Y}_{\text {est }}$ from trellis wire tension was compared with $\mathrm{Y}_{\mathrm{a}}$ at the processors' varying spatial scale of $\approx 10$ to 100 ha, not surprisingly, there was an increase in $\left|Y_{\text {err }}\right|$. Although our cooperating processors have reproducible sampling procedures, the inevitable constraints on time and labor have resulted in their establishing uniform sample sizes regardless of a sentinel vineyard's overall CV in yield (generally unknown in quantified terms, but often understood in general terms from subjective historical assessment by the grower or processor). Assuming identical sample sizes and identical cvs but different vineyard sizes, the error in predicted tonnage at harvest will be larger for a larger vineyard despite identical error rates (Wolpert and Vilas, 1992). One conundrum associated with questions of spatial scale is that processors are interested in regional yield predictions over their entire 


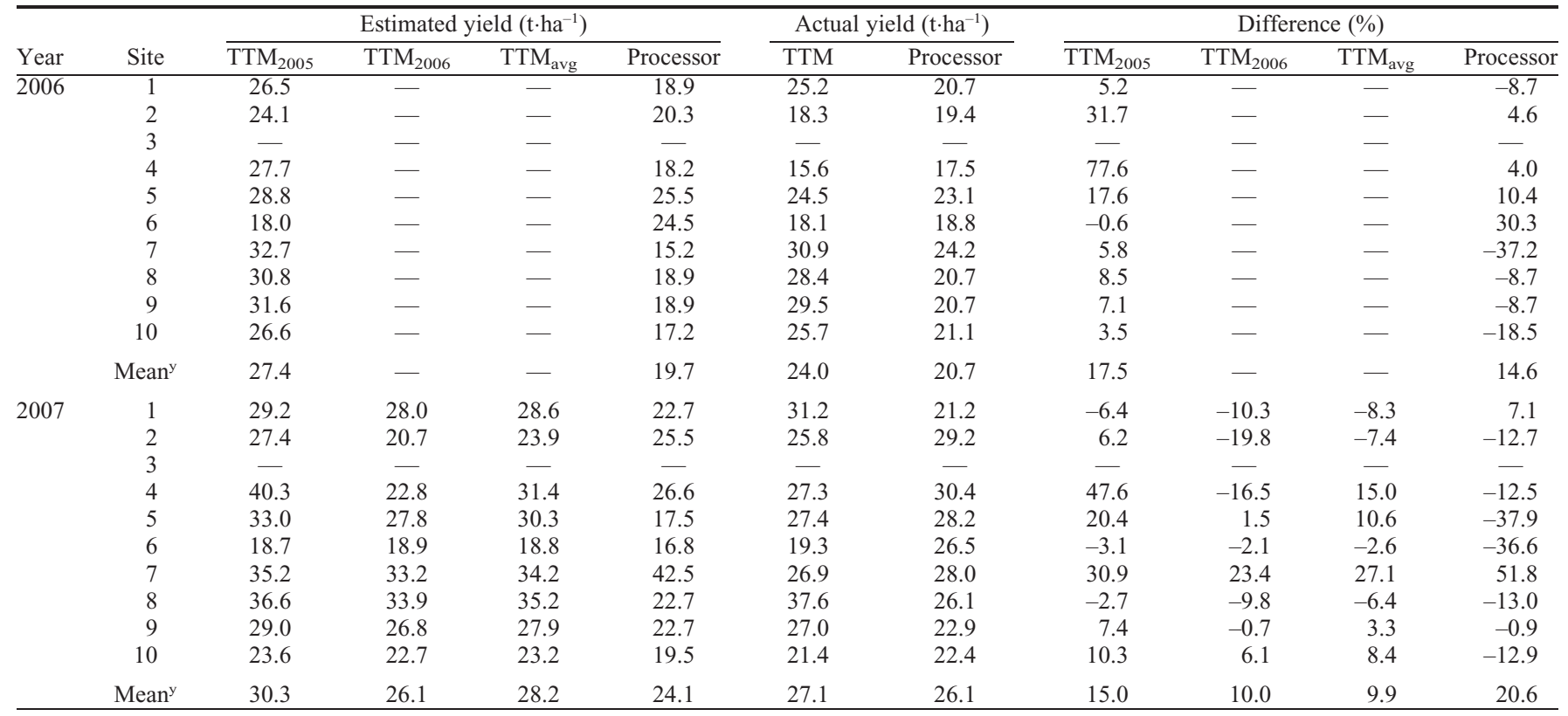

${ }^{2}$ Trellis tension monitor (TTM) yield was estimated using an individual antecedent year $\left(\mathrm{TTM}_{2005}\right.$ or $\left.\mathrm{TTM}_{2006}\right)$ or, in 2007, using the average of estimates from both antecedent years $\left(\mathrm{TTM}_{\mathrm{avg}}\right)$. Actual yield was that harvested from the 10 vines nearest the TTM. Processor yield estimates were based on 5 to 8 antecedent years, and actual yield was that harvested and delivered by the grower for the entire vineyard.

${ }^{y}$ Mean of absolute values of differences.

Table 5. Estimated and actual yield under comparative Approach 2 (equivalent spatial scales and temporal averaging) and the percent difference between the two for 10 'Concord' sites. ${ }^{2}$

\begin{tabular}{|c|c|c|c|c|c|c|}
\hline \multirow[b]{2}{*}{ Year } & \multirow[b]{2}{*}{ Site } & \multicolumn{2}{|c|}{ Estimated yield $\left(\mathrm{t} \cdot \mathrm{ha}^{-1}\right)$} & \multirow{2}{*}{$\frac{\text { Actual yield }\left(\mathrm{t} \cdot \mathrm{ha}^{-1}\right)}{\mathrm{TTM}}$} & \multicolumn{2}{|c|}{ Difference $(\%)$} \\
\hline & & TTM & Processor & & TTM & Processor \\
\hline \multirow[t]{11}{*}{2006} & 1 & 26.5 & 36.5 & 25.2 & 5.2 & 44.8 \\
\hline & 2 & 24.1 & 23.8 & 18.3 & 31.7 & 30.1 \\
\hline & 3 & - & - & - & - & - \\
\hline & 4 & 27.7 & 12.5 & 15.6 & 77.6 & -19.9 \\
\hline & 5 & 28.8 & 46.6 & 24.5 & 17.6 & 90.2 \\
\hline & 6 & 18.0 & 77.8 & 18.1 & -0.6 & 329.8 \\
\hline & 7 & 32.7 & 16.8 & 30.9 & 5.8 & -45.6 \\
\hline & 8 & 30.8 & 37.3 & 28.4 & 8.5 & 31.3 \\
\hline & 9 & 31.6 & 50.8 & 29.5 & 7.1 & 72.2 \\
\hline & 10 & 26.6 & 32.2 & 25.7 & 3.5 & 25.3 \\
\hline & Mean $^{y}$ & 27.4 & 37.1 & 24.0 & 17.5 & 76.6 \\
\hline \multirow[t]{11}{*}{2007} & 1 & 28.6 & 21.9 & 31.2 & -8.3 & -29.8 \\
\hline & 2 & 23.9 & 17.8 & 25.8 & -7.4 & -31.0 \\
\hline & 3 & - & - & - & - & - \\
\hline & 4 & 31.4 & 23.8 & 27.3 & 15.0 & -12.8 \\
\hline & 5 & 30.3 & 23.0 & 27.4 & 10.6 & -16.1 \\
\hline & 6 & 18.8 & 31.3 & 19.3 & -2.6 & 62.2 \\
\hline & 7 & 34.2 & 59.7 & 26.9 & 27.1 & 121.9 \\
\hline & 8 & 35.2 & 28.6 & 37.6 & -6.4 & -23.9 \\
\hline & 9 & 27.9 & 45.3 & 27.0 & 3.3 & 67.8 \\
\hline & 10 & 23.2 & 28.5 & 21.4 & 8.4 & 33.2 \\
\hline & Mean $y$ & 28.2 & 31.1 & 27.1 & 9.9 & 44.3 \\
\hline
\end{tabular}

${ }^{\mathrm{z}}$ Actual yield for comparison with both the trellis tension monitor (TTM) and processor estimates was that harvested from the 10 vines nearest the TTM. Input data for both the TTM and processor-based yield estimates were restricted to 2005 data for estimating 2006 and the average of 2005 and 2006 values for estimating 2007.

${ }^{y}$ Mean of absolute values of differences.

contracted acreage. Robust scaling up of trellis tension data from local estimates to vineyard or regional yield estimates requires further investigation to assess the number of TTMs that should be deployed to capture spatial variation adequately. This requirement is equally valid for determining an appropriate number and distribution of sentinel vines. The TTM does not resolve issues of spatial sampling within or among vineyards. At present, the functional niche for this method is in providing automation and temporal resolution that was not available previously.

Correction of $\Delta \mathrm{T}$ for the vegetative contribution to trellis tension could improve the dynamic accuracy of $Y_{t, c}$ and consequently $Y_{\text {est }}$. The observed error in $Y_{\text {est }}$ for the TTM may be driven substantially by interannual variation in the vines' ratio of fruit to vegetative masses. The smaller $\left|Y_{\text {err }}\right|$ in 2007 that resulted from using 2 rather than 1 antecedent year likely was driven by averaging the interannual variation in fruit:vegetative mass. This ratio is difficult to quantify dynamically (Tarara et al., 2009) and at present is approached most directly through destructive sampling, a deterrent to commercial adoption and a drawback in any perennial crop. Elsewhere, late-season (Stage III) dynamics of fruit fresh weight have been simulated for other fleshy fruits (e.g., peach) under various scenarios of crop load (Fishman and Génard, 1998). In grapevines, a statistical reconstruction model was developed recently to simulate canopy structure, expressed as leaf area density, and its variability (Louarn et al., 2008). With specific application to trellis tension monitoring, new $\mathrm{T}_{0}$ could be defined at phenological stages other than budbreak such as at bloom or when rates of shoot elongation or an increase in leaf area density become negligible (e.g., $\approx 600$ DD; Tarara et al., 2009).

Because the TTM continuously monitors accumulation of mass, daily updates of $\mathrm{Y}_{\mathrm{est}}$ can be made until harvest. Yield estimates derived under traditional protocols, which rely on a few static samples, have underestimated $\mathrm{Y}_{\mathrm{a}}$ in situations where berry mass was low during a standard sampling period. Interannual variation in the rate of berry development is well known (Rogiers et al., 2006). The rate of fruit growth may (or may not) be changed by water deficits depending on the timing, extent, and duration of the deficit (Matthews et al., 1987; McCarthy, 1997; Ojeda et al., 2002; Poni et al., 1994) or by other environmental stressors such as 
Table 6. Estimated and actual yield under comparative Approach 3 (spatial 'scaling up') and the percent difference between the two for 10 'Concord' sites. ${ }^{\text {. }}$

\begin{tabular}{|c|c|c|c|c|c|c|}
\hline \multirow[b]{2}{*}{ Year } & \multirow[b]{2}{*}{ Site } & \multicolumn{2}{|c|}{ Estimated yield $\left(\mathrm{t} \cdot \mathrm{ha}^{-1}\right)$} & \multirow{2}{*}{$\frac{\text { Actual yield }\left(\mathrm{t} \cdot \mathrm{ha}^{-1}\right)}{\text { Processor }}$} & \multicolumn{2}{|c|}{ Difference $(\%)$} \\
\hline & & TTM & Processor & & TTM & Processor \\
\hline \multirow[t]{11}{*}{2006} & 1 & 20.0 & 27.5 & 20.7 & -3.4 & 32.9 \\
\hline & 2 & 29.0 & 28.7 & 19.4 & 49.5 & 47.9 \\
\hline & 3 & - & - & - & - & - \\
\hline & 4 & 27.9 & 12.6 & 17.5 & 59.4 & -28.0 \\
\hline & 5 & 30.9 & 50.2 & 23.1 & 33.8 & 117.3 \\
\hline & 6 & 17.7 & 76.7 & 18.8 & -5.9 & 308.0 \\
\hline & 7 & 31.3 & 16.1 & 24.2 & 29.3 & -33.5 \\
\hline & 8 & 20.0 & 24.2 & 20.7 & -3.4 & 16.9 \\
\hline & 9 & 28.2 & 45.2 & 20.7 & 36.2 & 118.4 \\
\hline & 10 & 27.8 & 33.7 & 21.1 & 31.8 & 59.7 \\
\hline & Mean $^{\mathrm{y}}$ & 25.9 & 35.0 & 20.7 & 28.1 & 84.7 \\
\hline \multirow[t]{11}{*}{2007} & 1 & 22.6 & 21.0 & 21.2 & 6.6 & -0.9 \\
\hline & 2 & 27.3 & 23.4 & 29.2 & -6.5 & -19.9 \\
\hline & 3 & - & - & - & - & - \\
\hline & 4 & 32.9 & 22.9 & 30.4 & 8.2 & -24.7 \\
\hline & 5 & 30.7 & 23.7 & 28.2 & 8.9 & -16.0 \\
\hline & 6 & 19.0 & 31.2 & 26.5 & -28.3 & 17.7 \\
\hline & 7 & 29.8 & 50.4 & 28.0 & 6.4 & 80.0 \\
\hline & 8 & 24.2 & 22.6 & 26.1 & -7.3 & -13.4 \\
\hline & 9 & 22.3 & 50.6 & 22.9 & -2.6 & 121.0 \\
\hline & 10 & 21.6 & 27.0 & 22.4 & -3.6 & 20.5 \\
\hline & Mean $^{\mathrm{y}}$ & 25.6 & 30.3 & 26.1 & 8.7 & 34.9 \\
\hline
\end{tabular}

${ }^{\mathrm{z}}$ Actual yield for comparison with both the trellis tension monitor (TTM) and processor estimates was that harvested and delivered by the grower for the entire vineyard. Input data for both the TTM and processorbased yield estimates were restricted to 2005 data for estimating 2006 and the average of 2005 and 2006 values for estimating 2007.

${ }^{\mathrm{y}}$ Mean of absolute values of differences.

irradiance (Dokoozlian and Kliewer, 1996; Koyama and Goto-Yamamoto, 2008), nitrogen (reviewed by Keller, 2005), or temperature (Haselgrove et al., 2000; Kliewer, 1977). Although any number of variables may impinge on the rate of fruit growth, the combined effects of these variables are detected dynamically in an integrated fashion by $\Delta \mathrm{T}$. By using the TTM in conjunction with traditional estimation techniques, the grape industry could derive quantitative yield estimates earlier than presently allowed by traditional fruit sampling and could be apprized of late-season changes in the anticipated size of the crop that may suggest revision of earlier yield estimates.

\section{Conclusion}

This initial assessment of the TTM system's performance for yield estimation indicates that the method will have a place in the grape processors' tool kit. On average, the absolute error of prediction from the TTM was equal to or smaller than that from estimates derived from longstanding processor protocols. By caveat, comparing the TTM to conventional methods was not straightforward. At this time, processors have at their disposal extensive historical data sets from which they can select several antecedent years on which to base their prediction, whereas the TTM approach is novel and lacks substantial historical data. Over time, with expanded deployment of TTMs, we expect that more robust and extensive databases will improve the accuracy of yield estimates from trellis tension data. Spatial sampling issues remain as is still the case with traditional approaches to yield estimation in commercial vineyards.

\section{Literature Cited}

Bindon, K., P. Dry, and B. Loveys. 2008. Influence of partial rootzone drying on the composition and accumulation of anthocyanins in grape berries (Vitis vinifera cv. Cabernet Sauvignon). Aust. J. Grape Wine Res. 14:91-103.

Crippen, D.D. and J.C. Morrison. 1986. The effects of sun exposure on the compositional development of Cabernet Sauvignon berries. Amer. J. Enol. Viticult. 4:235-242.

Dokoozlian, N.K. and W.M. Kliewer. 1996. Influence of light on grape berry growth and composition varies during fruit development. J. Amer. Soc. Hort. Sci. 121:869-874.

Dunn, G.M. and S.R. Martin. 2004. Yield prediction from digital image analysis: A technique with potential for vineyard assessment prior to harvest. Aust. J. Grape Wine Res. 10: 196-198.

Fishman, S. and M. Génard. 1998. A biophysical model of fruit growth: Simulation of seasonal and diurnal dynamics of mass. Plant Cell Environ. 21:739-752.

Folwell, R.J., D.E. Santos, S.E. Spayd, L.H. Porter, and D.S. Wells. 1994. Statistical technique for forecasting Concord grape production. Amer. J. Enol. Viticult. 45:63-70.

Haselgrove, L., D. Botting, R. van Heeswijck, P.B. Høj, P.R. Dry, C. Ford, and P.G. Iland. 2000. Canopy microclimate and berry composition: The effect of bunch exposure on the phenolic composition of Vitis vinifera L. cv. Shiraz grape berries. Aust. J. Grape Wine Res. 6: 141-149.

Keller, M. 2005. Deficit irrigation and vine mineral nutrition. Amer. J. Enol. Viticult. 56:267-283.

Kliewer, W.M. 1977. Effect of high temperatures during the bloom-set period on fruit-set, ovule fertility, and berry growth of several grape cultivars. Amer. J. Enol. Viticult. 28:215222.

Kliewer, W.M. and H.B. Schultz. 1973. Effect of sprinkler cooling of grapevines on fruit growth and composition. Amer. J. Enol. Viticult. 24: $17-26$.

Kliewer, W.M. and R.J. Weaver. 1971. Effect of crop level and leaf area on growth, composition, and coloration of 'Tokay' grapes. Amer. J. Enol. Viticult. 22:172-177.

Koyama, K. and N. Goto-Yamamoto. 2008. Bunch shading during different developmental stages affects the phenolic biosynthesis in berry skins of 'Cabernet Sauvignon' grapes. J. Amer. Soc. Hort. Sci. 133:743-753.

Lamb, D.W., M.M. Weedon, and R.G.V. Bramley. 2004. Using remote sensing to predict grape phenolics and colour at harvest in a Cabernet Sauvignon vineyard: Timing observations against vine phenology and optimizing image resolution. Aust. J. Grape Wine Res. 10:4654.

Louarn, G., J. Lecouer, and E. Lebon. 2008. A three-dimensional statistical reconstruction model of grapevine (Vitis vinifera) simulating canopy structure variability within and between cultivar/training system pairs. Ann. Bot. (Lond.) 101:1167-1184.

Matsui, S., K. Ryugo, and W.M. Kliewer. 1991. Lowered berry quality due to heat stress at the early ripening stage of berry growth in a seeded grapevine, Vitis vinifera L. Res. Bull. Fac. Agr. Gifu Univ. 56:139-145.

Matthews, M.A., M.M. Anderson, and H.R. Schultz. 1987. Phenologic and growth responses to early and late season water deficits in Cabernet franc. Vitis 26:147-160.

May, P. Forecasting the grape crop. 1972. Austral. Wine, Brewing Spirit Rev. May 25. p. 46, 48.

McCarthy, M.G. 1997. The effect of transient water deficit on berry development of cv. Shiraz (Vitis vinifera L.). Aust. J. Grape Wine Res. 3:102-108.

Mpelasoka, B.S., D.P. Schachtman, M.T. Treeby, and M.R. Thomas. 2003. A review of potassium nutrition in grapevines with special emphasis on berry accumulation. Aust. J. Grape Wine Res. 9:154-168.

NASS. 2008. Noncitrus fruits and nuts 2007 summary. U.S. Dept. Agr., Natl. Agr. Stat. Serv. Fr Nt 1-3(08)a.

Ojeda, H., C. Andary, E. Kraeva, A. Carbonneau, and A. Deloire. 2002. Influence of pre- and postveraison water deficit on synthesis and concentration of skin phenolic compounds during berry growth of Vitis vinifera cv. Shiraz. Amer. J. Enol. Viticult. 53:261-267.

Pierce, F.J. and T.V. Elliott. 2008. Regional and on-farm wireless sensor networks for agricultural systems in eastern Washington. Comput. Electron. Agr. 61:32-43.

Poni, S., A.N. Lakso, J.R. Turner, and R.E. Melious. 1994. Interactions of crop level and late season water stress on growth and physiology of fieldgrown Concord grapevines. Amer. J. Enol. Viticult. 45:253-258.

Price, S.F. and P.B. Lombard. 1988. Predicting yield in Oregon vineyards. Proc. 2nd Intl. Cool Climate Viticulture and Oenology Symposium, Auckland, New Zealand. p. 197-200.

Rogiers, S.Y., D.H. Greer, J.M. Hatfield, B.A Orchard, and M. Keller. 2006. Solute transport into Shiraz berries during development and late-ripening stage. Amer. J. Enol. Viticult. 57: $73-80$.

Spayd, S.E. and R.L. Wample. 1995. Estimating yield for wine grapes. Practical Winery and Vineyard 15:6-11. 
Tarara, J.M., P.E. Blom, B. Shafii, W.J. Price, and M.A. Olmstead. 2009. Modeling seasonal dynamics of canopy and fruit growth in grapevine for application in automated yield estimation. HortScience 44:334-340.

Tarara, J.M., J.C. Ferguson, P.E. Blom, M. Pitts, and F.J. Pierce. 2004. Estimation of grapevine crop mass and yield via automated measurements of trellis tension. Trans. ASAE 47:647-657.
Tarara, J.M., J.C. Ferguson, M. Pitts, F.J. Pierce, G. Hyde, and R.L. Wample. 2005. Apparatus and method for measuring the mass of vegetation or fruit supported on a trellis. U.S. Patent No. 6854337. Issued $15 \mathrm{Feb}$.

Tobin, P.C., S. Nagarkatti, and M.C. Saunders 2001. Modeling development in Grape Berry Moth (Lepidoptera: Tortricidae). Environ. Entomol. 30:692-699.
Van Zyl, J.L. 1984. Response of Colombard grapevines to irrigation as regards quality aspects and growth. S. Afr. J. Enol. Viticul. 5:19-28.

Wine Business Monthly. 2006. Record California wine grape crush. Mar. 2006. p. 8.

Wolpert, J.A. and E.P. Vilas. 1992. Estimating vineyard yields: Introduction to a simple, twostep method. Amer. J. Enol. Viticult. 43:384388 . 